OPEN ACCESS

Edited by:

Imtiaz Ahmad Siddiqui, University of Colorado Anschutz Medical Campus, United States

Reviewed by:

Dongyu Zhang,

Georgetown University, United States

Tarjani Agrawal,

Independent Researcher, Jersey City,

NJ, United States

*Correspondence:

Xiao-Xi Fan

fanxx@cmu1h.com

Specialty section:

This article was submitted to

Cancer Epidemiology and Prevention,

a section of the journal

Frontiers in Oncology

Received: 31 October 2018

Accepted: 02 January 2019

Published: 22 January 2019

Citation:

Liu Y, Li Y, Bai Y-P and Fan X-X (2019) Association Between Physical Activity and Lower Risk of Lung Cancer: A Meta-Analysis of Cohort Studies. Front. Oncol. 9:5 doi: 10.3389/fonc.2019.00005

\section{Association Between Physical Activity and Lower Risk of Lung Cancer: A Meta-Analysis of Cohort Studies}

\author{
Yang Liu, Yue Li, Yun-Peng Bai and Xiao-Xi Fan* \\ Department of Thoracic Surgery, The First Affiliated Hospital of China Medical University, Shenyang, China
}

Background: Epidemiological evidences regarding the association between physical activity and the risk of lung cancer are still controversial.

Objectives: We aimed to investigate the relationship between physical activity and risk of lung cancer in men and women, as well as other high-risk populations such as cigarette smokers.

Methods: We conducted a meta-analysis of cohort studies to evaluate the association between physical activity and risk of lung cancer. Relevant studies were identified by searching PubMed and Web of Knowledge through August 2018. Study-specific relative risk (RR) with 95\% confidence interval $(\mathrm{Cl})$ were pooled using random effect model when significant heterogeneity was detected.

Results: Twenty cohort studies with a total of 2,965,811 participants and 31,807 lung cancer cases were included. There was an inverse association between the physical activity and risk of lung cancer. Compared with the low level of physical activity, the pooled RR was $0.83(95 \% \mathrm{Cl}: 0.77,0.90)$, with significant heterogeneity $\left(I^{2}=62.6 \%\right.$, $P$ heterogeneity $<0.001)$. The corresponding pooled RRs were 0.90 (95\% Cl: $0.82,0.99)$ for women and $0.81(95 \% \mathrm{Cl}: 0.73,0.90)$ for men. Smokers with a high level of physical activity were associated with a 10\% lower risk for lung cancer $(R R=0.90,95 \%$ $\mathrm{Cl}$ : 0.84, 0.97), while the association was not significant among non-smokers (RR $=0.95,95 \% \mathrm{Cl}: 0.88,1.03)$. Subgroups analysis stratified by whether the studies adjusted for smoking intensity and durations yielded the same magnitude of RR. However, the RR for subgroups without adjustment for dietary factors was 0.74 $(95 \% \mathrm{Cl}: 0.71,0.77)$, which was significantly lower than that with dietary factors adjusted $(\mathrm{RR}=0.89,95 \% \mathrm{Cl}: 0.84,0.95)$.

Conclusions: Increased physical activity might be associated with lower risk of lung cancer. Such inverse association was identified among smokers rather than non-smokers. Large interventional studies are expected to further verify these findings.

Keywords: physical activity, lung cancer, smoking, cohort study, meta-analysis 


\section{INTRODUCTION}

The global burden of lung cancer has been increasing over the past years. It is the most frequently diagnosed cancer and the leading cause of cancer death, accounting for 11.6\% (2,093,876 new cases) of the total new cancer cases and $18.4 \%(1,761,007$ deaths) of the total cancer deaths in 2018 (1). As such, primary prevention of lung cancer is therefore a critical public health challenge worldwide.

Cumulative observational evidences suggested that physical activity may be significantly associated with a reduced risk of lung cancer (2-7), while others did not observed such an association (8-12). Of note, it has been reported that physical activity was unrelated to lung cancer among never smokers but it was inversely associated with lung cancer among former and current smokers $(13,14)$. Previous meta-analysis with both cohort studies and case-control studies have detected an inverse association between physical activity and risk of lung cancer $(14,15)$. Since potential selection and recall bias related to the design of case-control study might distort the true association, the relationship is still unclear. Thus, the International Agency of Research in Cancer concluded that the association between physical activity and risk of lung cancer remained inconclusive (16). In addition, a protective effect of physical activity on lung cancer was categorized as limited evidence in the World Cancer Research Fund/American Institute for Cancer Research report from 2007-2018.

Recently, several large prospective cohorts have evaluated the association of physical activity with lung cancer $(6,7,12,17,18)$. A prospective study of seven Australian cohorts with $3,67,058$ participants reported a significantly inverse association in men, but not in women, suggesting a possible gender disparity for relationship (7). Moreover, the Physical Activity Collaboration of the National Cancer Institute's Cohort Consortium with 1.44 million adults reported that smoking status modified the association for lung cancer (6). It is still unclear whether the association between physical activity and lung cancer is the result of an underestimation of lifetime smoking; and therefore a better understanding of this association in never smokers is needed.

Thus, an integration with these most up-to-date evidences from these large cohorts may address these issues and make it possible to detect the association, as well as the possible effect modifications by smoking status and gender. Since evidences from large prospective cohort studies with less potential bias are more convince, we aimed at conducting an updated metaanalysis including only cohort studies to quantitatively assess the association between physical activity with risk of lung cancer.

\section{MATERIALS AND METHODS \\ Data Sources and Search Strategy}

This meta-analysis was reported using the Preferred Reporting Items for Systematic reviews and Meta-Analyses guidelines (19). A literature search through August 2018 was performed using PubMed and Web of Knowledge with the combination

Abbreviations: RR, relative risk; $\mathrm{CI}$, confidence interval. of the following key words: ("physical activity" or "exercise") and ("cancer" or "neoplasm" or "carcinoma" or "tumor") and "lung" and "cohort." In addition, we also manually searched the reference lists of relevant publications to identify additional studies.

\section{Studies Selections and Data Extraction}

The study selection process consisted of title/abstract screening and full-text review. In the title/abstract screening stage, records were identified based on their relevance to the study topic, i.e., whether the study used a cohort design and presented the information on physical activity as the exposure of interest and incident lung cancer as the outcome of interest. In the fulltext review stage, studies were included if they further provided relative risk (RR), hazard ratio or risk ratio of highest level vs. lowest level as risk estimates with the corresponding 95\% confidence intervals (CIs) or standard errors. We used the RR as the measure of the association between physical activity and risk of lung cancer. If multiple estimates were provided, priority was given to the multivariable adjusted risk estimates. Instances in which data were insufficient or missing, we attempted to contact the authors of the articles to request the relevant data. Two authors (Yang Liu and Yue Li) independently performed the literature search and study selection. Discrepancies were resolved by discussion with other reviewer (Xiao-Xi Fan).

Two researchers (Xiao-Xi Fan and Yun-Peng Bai) independently used a standardized reporting form to abstract the following data from each study: the first author's name, the year of publication, the country in which the study was performed, the duration of follow-up, number of study population, the number of lung cancer events, the assessment of physical activity, the study outcome, the categories of exposure with the corresponding RRs and 95\% CIs, the covariates adjusted in multivariable models.

\section{Quality Assessment}

To assess study quality, a 9-point system on the basis of the Newcastle-Ottawa Scale was used in which a study was judged on 3 broad categories for cohort studies as follows: the selection of study groups, comparability of groups, and ascertainment of either the exposure or outcome of interest (20).

\section{Data Analysis}

To examine associations between of physical activity and risk of lung cancer, we used the random effect model proposed by DerSimonian and Laird to pool the study specific estimates if significant heterogeneity was observed (21). Subgroup analyses were conducted to explore the potential sources of heterogeneity. Subgroup analyses were conducted stratified by gender, study location, size of cohort, exposure assessment, outcome assessment, smoking status, and whether the studies adjusted for potential confounders or risk factors. We also performed a sensitivity analysis of the influence of individual studies on the pooled estimates by repeating the meta-analysis excluding one study at a time. Heterogeneity among studies was assessed with the $\mathrm{Q}$ and the $I^{2}$ statistics and results were defined as heterogeneous for a $P$-value $<0.10$ or an $I^{2}$ 


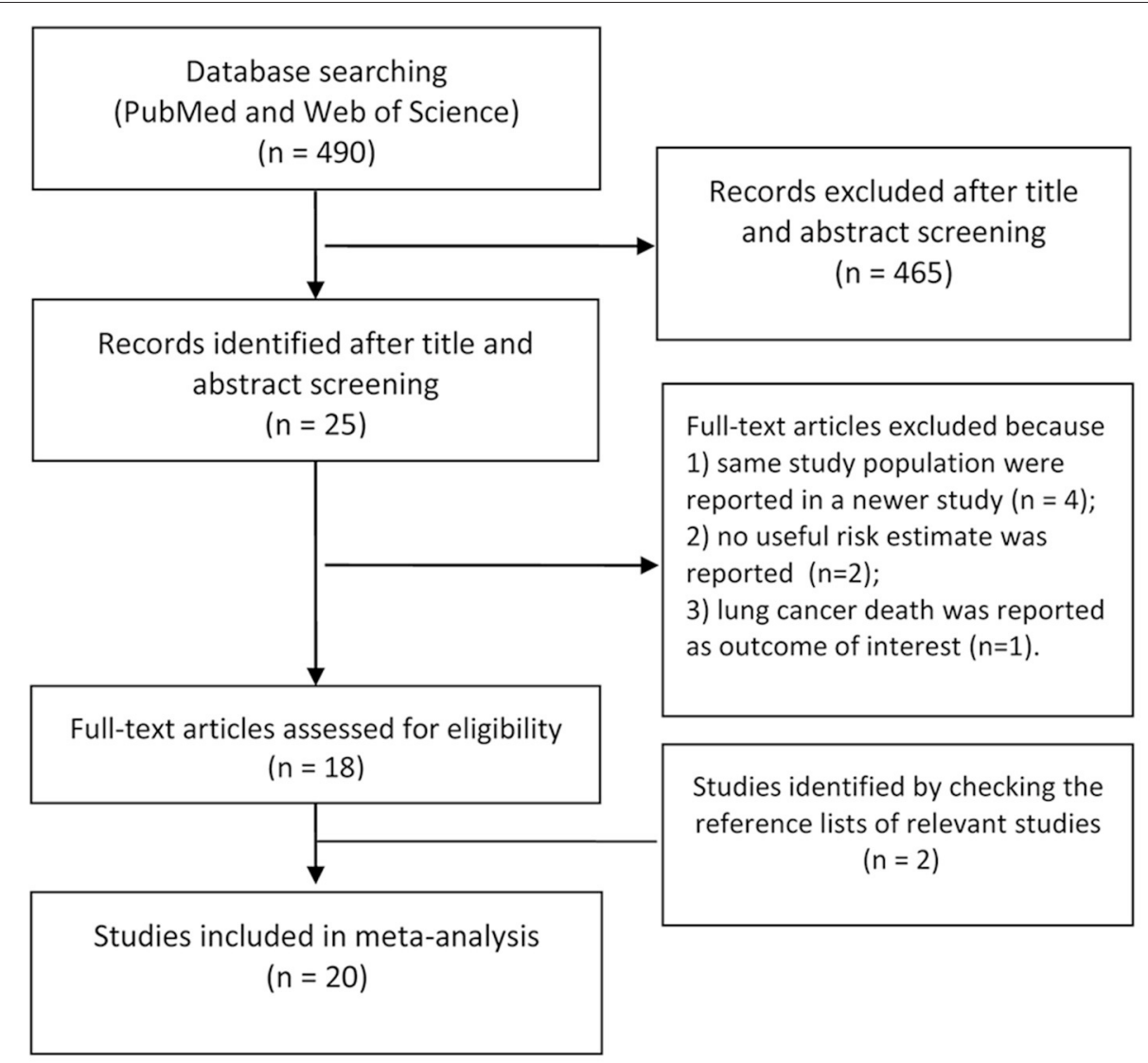

FIGURE 1 | Flow chart of the selection of studies in this meta-analysis.

$>50 \%$ (22). Publication bias were evaluated by Begg's (23), Egger's tests (24) and arcsine-Thompson test (25). The trim and fill method was employed to adjust for potential publication bias (26).

Statistical analyses were conducted using Stata (version 13.0). Two-sided $P$-values of $<0.05$ were considered statistically significant.

\section{RESULTS}

\section{Literature Search, Study Characteristics and Quality Assessment}

A flow diagram for the search is presented in Figure 1. A total of 490 records were identified from the 2 databases. After review of the titles and abstracts, 465 records were excluded because of little relevance to the study topic. After reviewing the full text of the remaining 25 cohort studies, four studies (27-30) were excluded as same study population were reported in the newer study; two studies $(31,32)$ were excluded as no RRs or $95 \%$ CIs were reported; One (33) was excluded because of reporting the lung cancer death as the outcome of interest. Two additional studies $(5,34)$ were identified by checking the reference lists of relevant articles. Thus, we included 20 cohort studies in the final analysis $(2-12,17,18,34-40)$.
Descriptive data for the 20 included cohort studies were summarized in Table 1 . There was a total of $2,965,811$ cohort members, of whom 31,807 developed lung cancer during followup. Eight studies were conducted in the United States, 8 studies in European countries, 2 in Asian countries, and 2 in others areas. The study population were adults with age of $>18$ years. Most studies were adjusted for major confounders including age, sex, smoking status, and body mass index, etc.

The quality scores ranged from 5 to 9 with a median score of 8 . Three studies were evaluated with a score of $<7$, and others with a score of $\geq 7$. Thus, the majority of the studies included in the meta-analysis were assessed as high-quality studies (Supplementary Table 1).

\section{Synthesized Findings}

As shown in Figure 2, seven studies reported statistically significant inverse associations and the others showed null associations. The overall analysis of the 20 studies showed an inverse association between the physical activity and risk of lung cancer, which indicated that increased physical activity may be associated with a lower the risk of lung cancer. Compared with the low level of physical activity, the pooled RRs were 0.83 (95\%CI: $0.77,0.90)$, with significant heterogeneity $\left(I^{2}=62.6 \%\right.$, $P$ heterogeneity $<0.001)$ across the included studies. Publication 


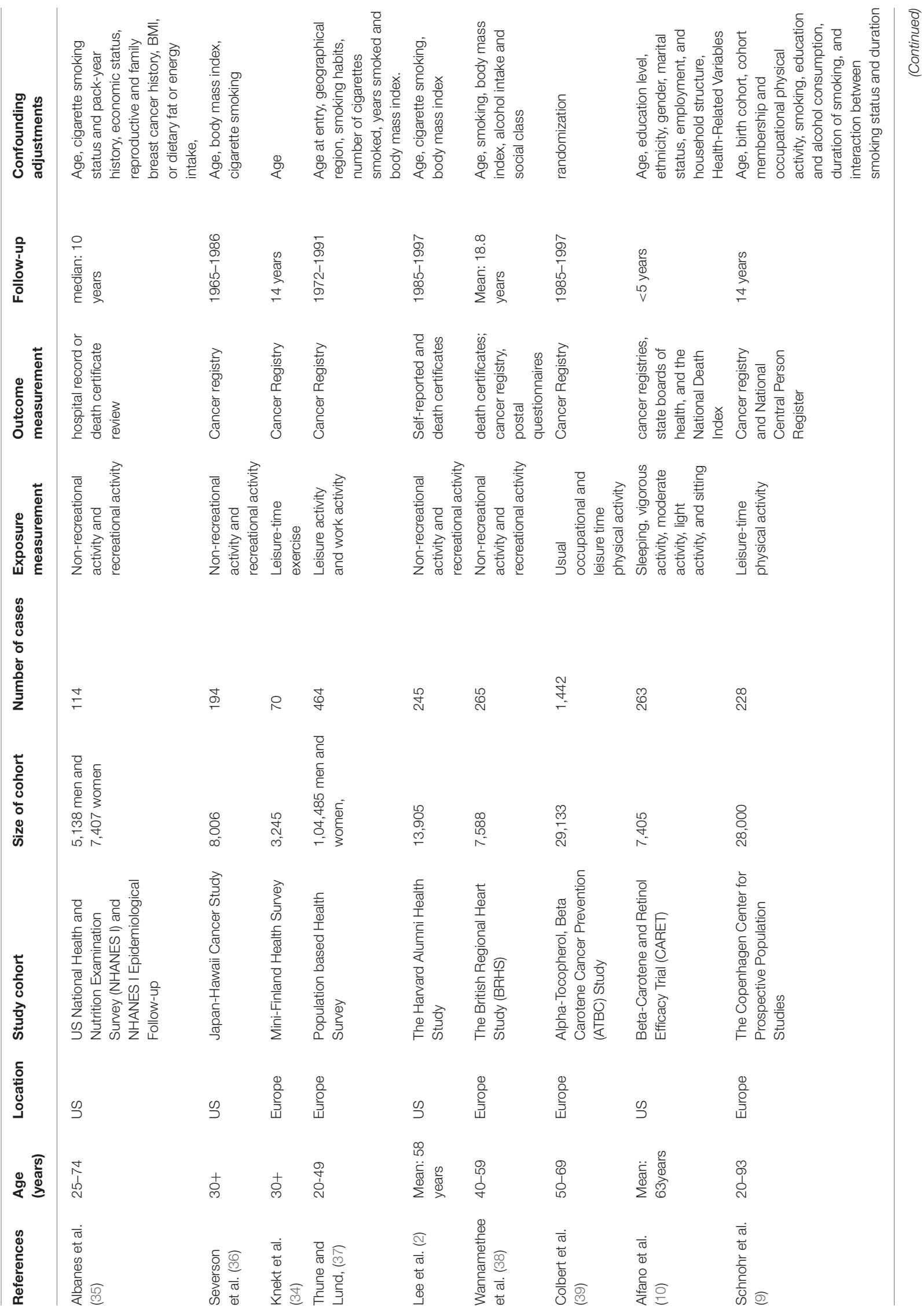




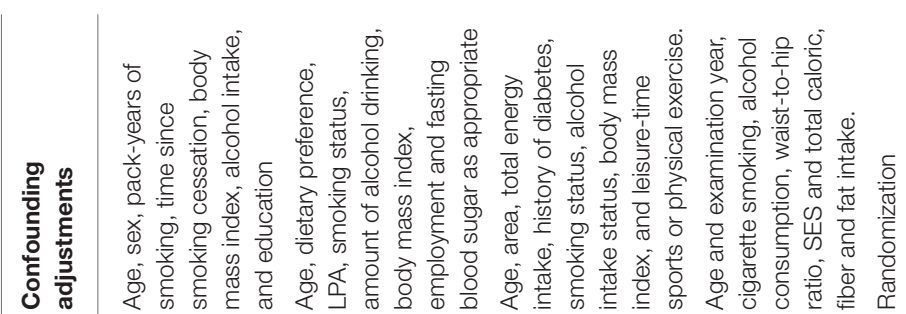

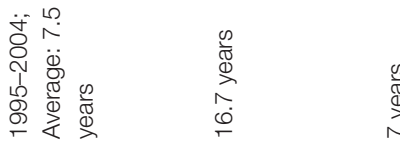

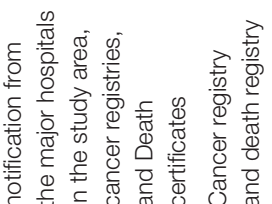

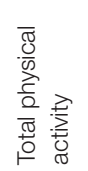

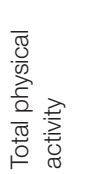

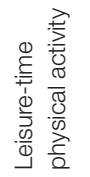

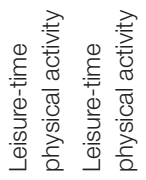

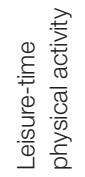

న్లి

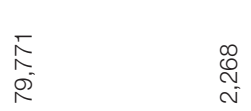
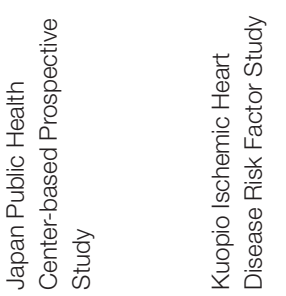

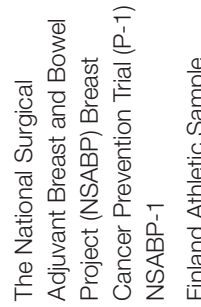

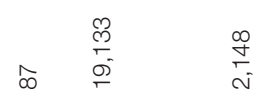

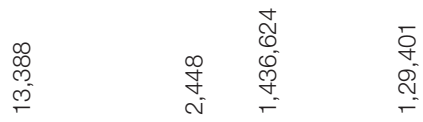

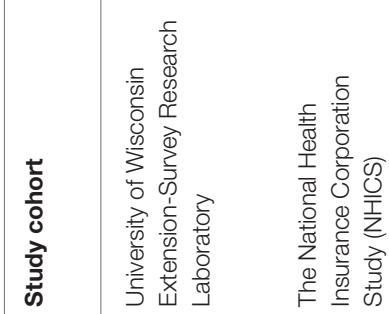

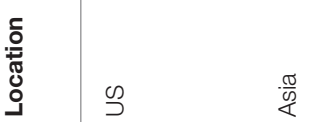

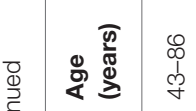

+a

$\frac{\pi}{\frac{\pi}{4}}$

$\stackrel{0}{\stackrel{0}{\circ}}$

孛

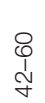

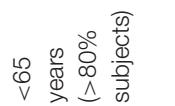

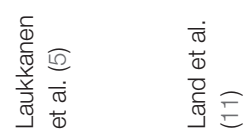

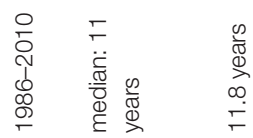

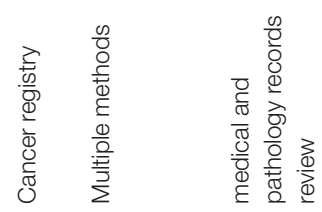

$\frac{1}{\frac{1}{0}}$

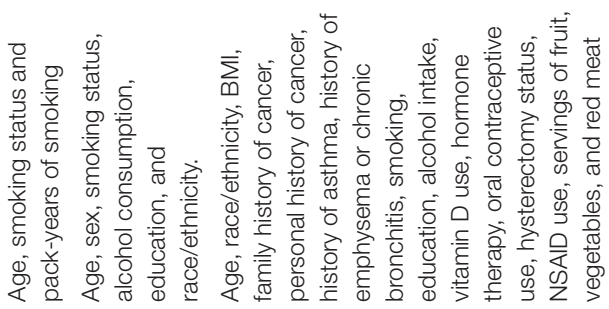




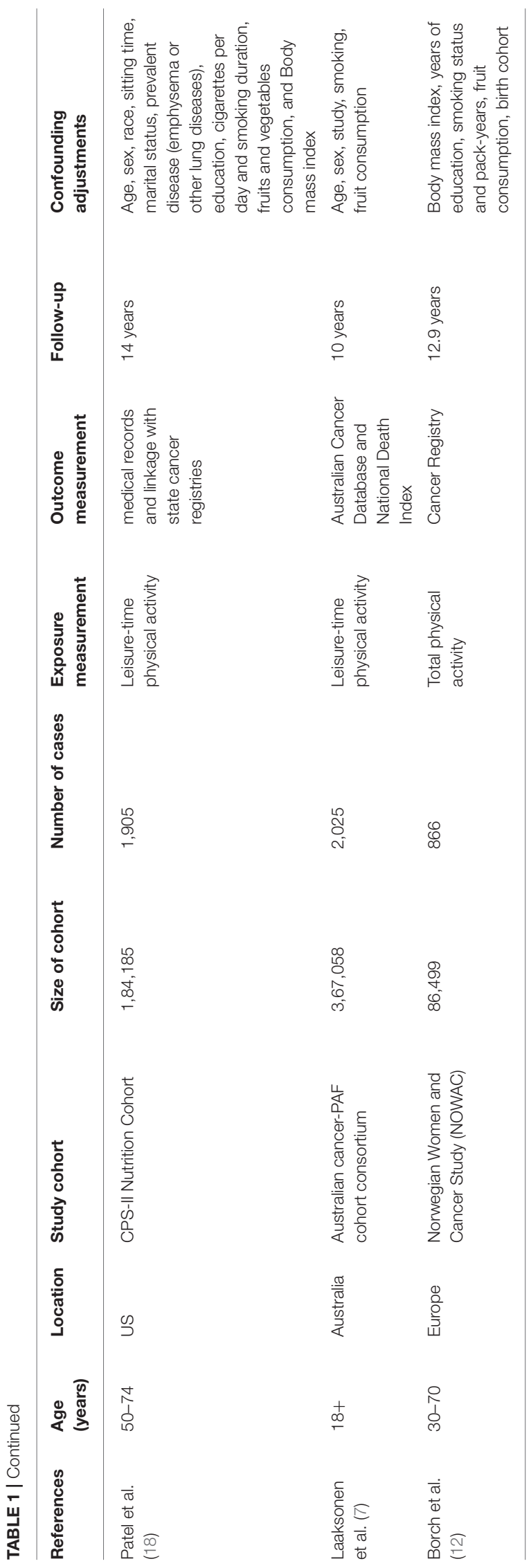

bias were tested by Egger's test $(P=0.414)$, Begg's test $(P=$ $0.023)$ and arcsine-Thompson test $(P=0.151)$. The funnel plot was shown in Figure 3. Furthermore, when attempting to use the trim and fill method to adjust for potential publication bias, no additional studies have been added, resulting in it having the same pooled RR and 95\% CI as the original estimate. Taken together, there might be little indication of publication bias in this meta-analysis.

Subgroup analyses for the association between physical activity and risk of lung cancer was shown in Table 2. Consistent with the overall analysis, a significant inverse association was observed in most of the subgroups. Compared with women with low level of physical activity, the pooled RRs for those with high level of physical activity were 0.90 (95\%CI: $0.82,0.99)$. The corresponding RR for men was 0.81 (95\%CI: $0.73,0.90)$. The RR for leisure time physical activity was 0.81 (95\% CI: 0.71, 0.93), which was comparable with total physical activity $(\mathrm{RR}=0.81$, $95 \%$ CI: 0.71, 0.93). Smokers with a high level of activity was associated with a $10 \%$ lower in risk of lung cancer risk $(\mathrm{RR}=$ $0.90,95 \%$ CI: $0.84,0.97$ ), while the association was not significant among non-smokers ( $\mathrm{RR}=0.95,95 \% \mathrm{CI}: 0.88,1.03)$. Of note, subgroups with whether or not adjusted for smoking intensity and durations yielded the same magnitude of RR. However, the RR for subgroups without adjustment for dietary factors was 0.74 (95\%CI: $0.71,0.77$ ), which was significantly lower than that with dietary factors adjusted ( $\mathrm{RR}=0.89,95 \% \mathrm{CI}$ : $0.84,0.95)$.

In sensitivity analyses, we recalculated the pooled RRs by sequentially excluding one study. The pooled RRs ranged from 0.82 (95\% CI: $0.76,0.89)$ to 0.86 (95\% CI: $0.81,0.92)$. The trend was generally similar with the overall analysis (Supplementary Figure 1).

\section{CONCLUSIONS}

In summary, this meta-analysis suggest that the increased physical activity might be associated with lower risk of lung cancer. Such inverse association was identified among smokers rather than non-smokers. Large interventional studies are expected to further verify these findings. If the inverse association, as well as the effect modification by smoking status, reflects a causal relation, future precision prevention of lung cancer by increased physical activity may be more effective when targeting to smokers rather than non-smokers.

\section{DISCUSSION}

\section{Summary of Main Findings}

In this meta-analysis of cohort studies, there was an inverse association between physical activity and risk of lung cancer. Increased physical activity may be associated with lower risk of lung cancer. The strength of association in men was stronger than that in women. Similar inverse association was observed in smokers, whereas no significant associations were found in never smokers. The observed inverse associations were robust across subgroups and sensitivity analyses.

Previous meta-analysis including both case-control studies and cohort studies suggested that regular recreational physical 


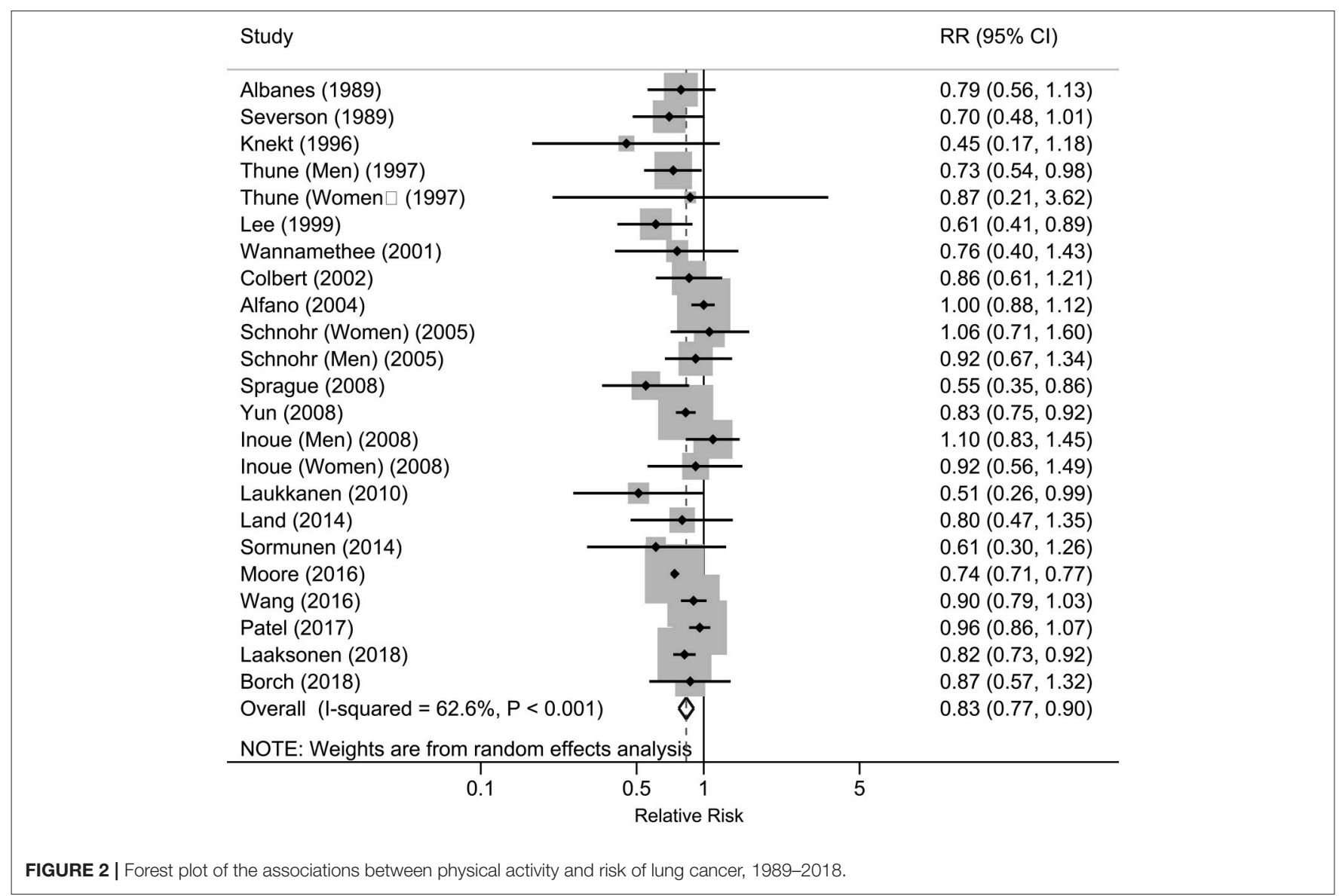

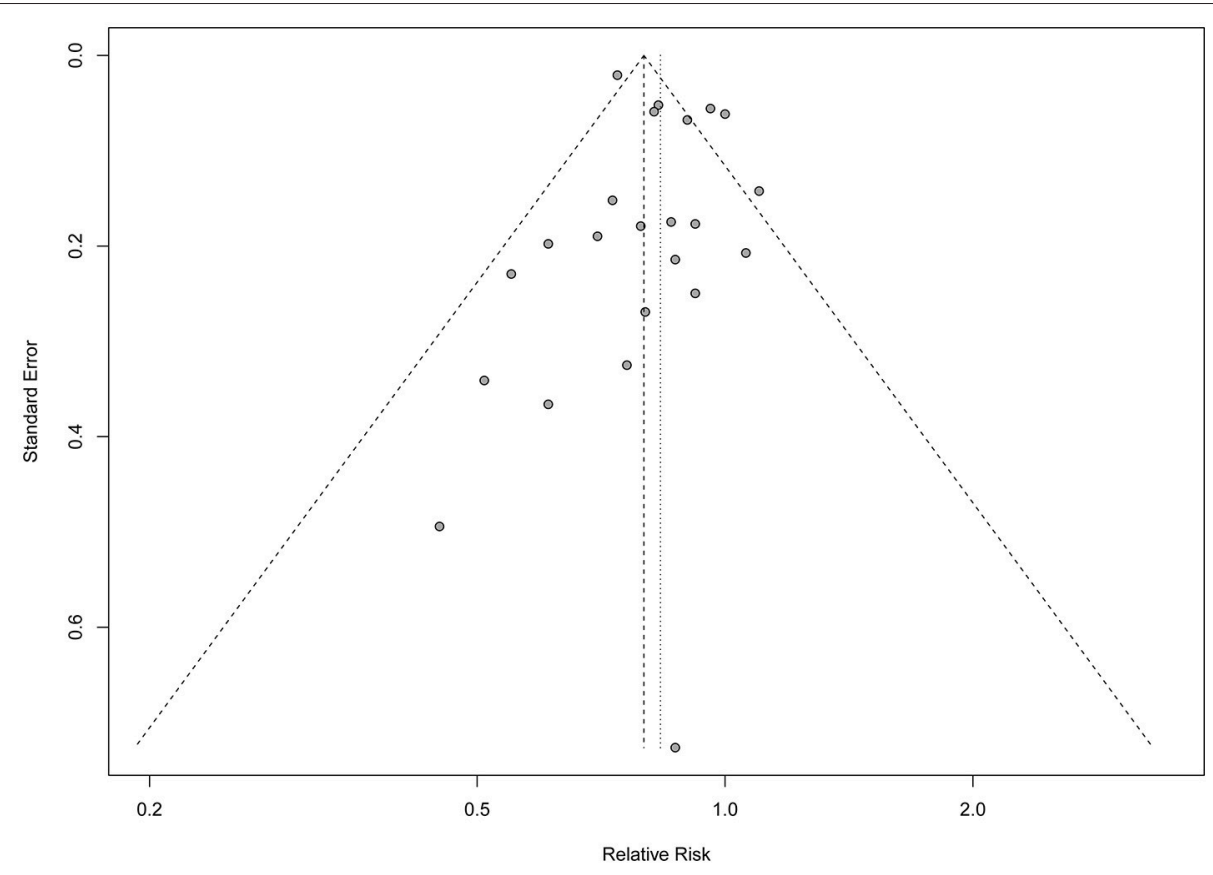

FIGURE 3 | Funnel plot of the meta-analysis. 
TABLE 2 | Subgroup results of association between physical activity and lung cancer risk.

\begin{tabular}{|c|c|c|c|c|c|}
\hline Subgroups & Number of studies & $\begin{array}{l}\text { Pooled RR } \\
(95 \% \mathrm{Cl})\end{array}$ & $I^{2}(\%)$ & $P$-value* & $P$-value ${ }^{t}$ \\
\hline Gender & & & & & 0.265 \\
\hline Women & 8 & $0.90(0.82,0.99)$ & 0 & 0.984 & \\
\hline Location & & & & & 0.500 \\
\hline Asia & 2 & $0.91(0.75,1.10)$ & 43.4 & 0.171 & \\
\hline Others & 2 & $0.77(0.70 .0 .85)$ & 62.9 & 0.101 & \\
\hline Size of Cohorts & & & & & 0.473 \\
\hline$<50,000$ & 12 & $0.79(0.68,0.91)$ & 41.1 & 0.06 & \\
\hline$\geq 50,000$ & 8 & $0.85(0.78,0.94)$ & 73.1 & $<0.001$ & \\
\hline Outcome measurement & & & & & 0.726 \\
\hline Cancer registry & 16 & $0.84(0.77,0.92)$ & 66.5 & $<0.001$ & \\
\hline Others & 4 & $0.81(0.70,0.97)$ & 19.9 & 0.29 & \\
\hline Smoking status & & & & & 0.598 \\
\hline Smokers & 6 & $0.90(0.84,0.97)$ & 36.5 & 0.164 & \\
\hline Non-smokers & 5 & $0.95(0.88,1.03)$ & 24.3 & 0.259 & \\
\hline \multicolumn{6}{|c|}{ ADJUSTMENT FOR POTENTIAL CONFOUNDERS OR RISK FACTORS } \\
\hline Smoking intensity/durations & & & & & 0.761 \\
\hline No & 12 & $0.84(0.77,0.93)$ & 69.9 & $<0.001$ & \\
\hline Yes & 8 & $0.84(0.74,0.95)$ & 17.1 & 0.291 & \\
\hline Body mass index & & & & & 0.247 \\
\hline Yes & 11 & $0.89(0.84,0.95)$ & 25.1 & 0.197 & \\
\hline
\end{tabular}

*P for heterogeneity within subgroups.

$t_{P}$ for heterogeneity between subgroups.

activity may be associated with reduced risk of lung cancer, with a pooled RR of 0.76 (95\% CI: 0.69-0.85) (14). This pooled result was attenuated in current study with only cohort studies included in the meta-analysis. This inconsistence may be due to large numbers of case-controls studies included in previous meta-analysis, and the case-control design may be more likely to expose to high risk of biases, such as selection bias, recall bias and inverse causal bias, which may distort the true association. Furthermore, previous meta-analysis concluded that the risk was lower in women than that in men (RR: 0.68 for women, 0.85 for men) (15), which was inconsistent with the results of current study (RR: 0.90 for women: 0.81 for men) with the up-to-date evidence included in the analysis.

In current meta-analysis, there were significantly heterogeneous results across subgroups stratified by whether the included studies adjusted for the dietary factors. Although both of the subgroups showed significant results, the strength of the association differed. The dietary factors such as total energy intake may mutually interact with physical activity and be associated with lung cancer as either a confounder or an intermediate factor, which may subsequently lead to the heterogeneous results across subgroups. Moreover, heterogeneity may also exist across the subgroups stratified by smoking status. A significant inverse associations between physical activity and lung cancer risk were observed among smokers, but not among never smokers. One of the largest study (6) with pooled data of 12 prospective US and European cohorts observed a significant effect modification by smoking status, with an inverse association in smokers rather than non-smokers. Of note, previous studies explained the heterogeneity as a result of residual confounding 
by smoking intensity and durations. However, we stratified by whether the included studies adjusted for the smoking intensity and durations in current meta-analysis, yielding the similar RR of 0.84 in both subgroups, which may rule out the possibility of residual confounding by smoking intensity.

It is suggested that physical activity increases pulmonary function, which may reduce the duration of exposure to carcinogenic agents in the lung (41). Several epidemiologic studies have shown that elevated lung function is associated with reduced lung cancer risk (41-43). Randomized trials showed that a 1 year physical activity intervention reduced levels of estrone and estradiol, which play key roles in lung carcinogenesis and lung cancer growth $(41,44)$. In addition, multiple potential biological mechanisms, including inflammation, and oxidative stress have long been hypothesized underlying the observed association between physical activity and lung cancer (41, 42). Physical activity may decrease body fat, interleukin-6 and tumor necrosis factor- $\alpha$ (42). The decreased levels of interleukin- 6 and tumor necrosis factor- $\alpha$ may be associated with lower risk of lung cancer (42). Previous study indicated that more frequent physical activity was associated with a lower odds of having an elevated C-reactive protein, fibrinogen and reactive oxygen species levels (45). The increased levels of reactive oxygen species are extensively involved in the mechanisms of chronic lung inflammation and thus contribute to the development of lung cancer $(46,47)$. However, these biological mechanisms oxidative stress and cancer development are still controversial. Oxidative stress can cause tumor initiation if they damaged DNA; however, oxidative stress has also been shown to help kill early tumor cells in process of tumor promotion (48). Since the exact mechanism of physical activity on lung carcinogenesis remains unclear, further research is still warranted.

\section{Limitations}

Our study also has some limitations. First, because of the nature of the observational design, residual confounding may distort the observed association and we were not able to address problems with confounding inherent in the original studies. For

\section{REFERENCES}

1. Bray F, Ferlay J, Soerjomataram I, Siegel RL, Torre LA, Jemal A. Global cancer statistics 2018: GLOBOCAN estimates of incidence and mortality worldwide for 36 cancers in 185 countries. CA Cancer J Clin. (2018) 68:394-424. doi: $10.3322 /$ caac. 21492

2. Lee IM, Sesso HD, Paffenbarger RS, Jr. Physical activity and risk of lung cancer. Int J Epidemiol. (1999) 28:620-5. doi: 10.1093/ije/28.4.620

3. Sprague BL, Trentham-Dietz A, Klein BE, Klein R, Cruickshanks KJ, Lee $\mathrm{KE}$, et al. Physical activity, white blood cell count, and lung cancer risk in a prospective cohort study. Cancer Epidemiol Biomarkers Prev. (2008) 17:2714-22. doi: 10.1158/1055-9965.EPI-08-0042

4. Yun YH, Lim MK, Won Y-J, Park SM, Chang YJ, Oh SW, et al. Dietary preference, physical activity, and cancer risk in men: national health insurance corporation study. BMC Cancer (2008) 8:366. doi: 10.1186/1471-2407-8-366

5. Laukkanen JA, Pukkala E, Rauramaa R, Makikallio TH, Toriola AT, Kurl S. Cardiorespiratory fitness, lifestyle factors and cancer risk and mortality in Finnish men. Eur J Cancer (2010) 46:355-63. doi: 10.1016/j.ejca.2009.07.013

6. Moore SC, Lee IM, Weiderpass E, Campbell PT, Sampson JN, Kitahara $\mathrm{CM}$, et al. Association of leisure-time physical activity with risk of 26 types example, dietary factors such as total energy intake may affect physical activity and be associated with risk of lung cancer. The lack of data on chronic lung disease may probably bias the results. However, most studies included in this meta-analysis adjusted for some of the major potential confounders, such as age, sex, smoking status, body mass index. To overcome this limitation, large randomized trials would be necessary to definitively verify the observed association. Second, there was a significant heterogeneity in current meta-analysis. There are several potential explanations for the observed between-study heterogeneity, such as different type of physical activity, different measurement of physical activity, various size of cohort and length of follow-up from study to study. Since all these together may result in statistical heterogeneity, the results of current study should be interpreted with caution. Despite these limitations, the major strength of this meta-analysis was the large sample size which provided sufficient statistical power to detect a significant association, as well as across various subgroups.

\section{AUTHOR CONTRIBUTIONS}

YaL and X-XF contributed to the conception or design of the work. X-XF and YaL contributed to the acquisition, analysis, or interpretation of data for the work. YaL drafted the manuscript. YuL and Y-PB critically revised the manuscript. All authors gave final approval and agree to be accountable for all aspects of work ensuring integrity and accuracy.

\section{ACKNOWLEDGMENTS}

We appreciated Dr. Dan Zhao for her suggestions and supports on the statistical analysis of this study.

\section{SUPPLEMENTARY MATERIAL}

The Supplementary Material for this article can be found online at: https://www.frontiersin.org/articles/10.3389/fonc. 2019.00005/full\#supplementary-material

of cancer in 1.44 million adults. JAMA Intern Med. (2016) 176:816-25. doi: 10.1001/jamainternmed.2016.1548

7. Laaksonen MA, Canfell K, MacInnis R, Arriaga ME, Banks E, Magliano DJ, et al. The future burden of lung cancer attributable to current modifiable behaviours: a pooled study of seven Australian cohorts. Int J Epidemiol. (2018) 47:1772-83. doi: 10.1093/ije/dyy136

8. Inoue M, Yamamoto S, Kurahashi N, Iwasaki M, Sasazuki S, Tsugane S. Daily total physical activity level and total cancer risk in men and women: results from a large-scale population-based cohort study in japan. Am J Epidemiol. (2008) 168:391-403. doi: 10.1093/aje/kwn146

9. Schnohr P, Gronbaek M, Petersen L, Hein HO, Sorensen TI. Physical activity in leisure-time and risk of cancer: 14-year follow-up of 28,000 Danish men and women. Scand J Public Health (2005) 33:244-9. doi: 10.1080/14034940510005752

10. Alfano CM, Klesges RC, Murray DM, Bowen DJ, McTiernan A, Vander Weg MW, et al. Physical activity in relation to all-site and lung cancer incidence and mortality in current and former smokers. Cancer Epidemiol Biomarkers Prev. (2004) 13:2233-41. doi: 10.3109/13547500903186452

11. Land SR, Liu Q, Wickerham DL, Costantino JP, Ganz PA. Cigarette smoking, physical activity, and alcohol consumption as predictors of 
cancer incidence among women at high risk of breast cancer in the NSABP P-1 trial. Cancer Epidemiol Biomarkers Prev. (2014) 23:823-32. doi: 10.1158/1055-9965.epi-13-1105-t

12. Borch KB, Weiderpass E, Braaten T, Hansen MS, Licaj I. Risk of lung cancer and physical activity by smoking status and body mass index, the Norwegian Women and Cancer Study. Eur J Epidemiol. (2018). doi: 10.1007/s10654-018-0446-0. [Epub ahead of print].

13. Schmid D, Ricci C, Behrens G, Leitzmann MF. Does smoking influence the physical activity and lung cancer relation? A systematic review and metaanalysis. Eur J Epidemiol. (2016) 31:1173-90. doi: 10.1007/s10654-016-0186-y

14. Brenner DR, Yannitsos DH, Farris MS, Johansson M, Friedenreich CM. Leisure-time physical activity and lung cancer risk: a systematic review and meta-analysis. Lung Cancer (2016) 95:17-27. doi: 10.1016/j.lungcan.2016.01.021

15. Buffart LM, Singh AS, van Loon EC, Vermeulen HI, Brug J, Chinapaw MJ. Physical activity and the risk of developing lung cancer among smokers: a meta-analysis. J Sci Med Sport (2014) 17:67-71. doi: 10.1016/j.jsams.2013.02.015

16. World Cancer Research Fund/American Institute for Cancer Research. Continuous Update Project Expert Report 2018. Diet n, physical activity and lung cancer. Available online at: www.dietandcancerreport.org

17. Wang A, Qin F, Hedlin H, Desai M, Chlebowski R, Gomez S, et al. Physical activity and sedentary behavior in relation to lung cancer incidence and mortality in older women: the women's health initiative. Int J Cancer (2016) 139:2178-92. doi: 10.1002/ijc.30281

18. Patel AV, Carter BD, Stevens VL, Gaudet MM, Campbell PT, Gapstur SM. The relationship between physical activity, obesity, and lung cancer risk by smoking status in a large prospective cohort of US adults. Cancer Causes Control (2017) 28:1357-68. doi: 10.1007/s10552-017-0949-0

19. Moher D, Liberati A, Tetzlaff J, Altman DG, Group P. Preferred reporting items for systematic reviews and meta-analyses: the PRISMA statement. PLoS Med. (2009) 6:e1000097. doi: 10.1371/journal.pmed.1000097

20. Wells GA Shea B, O'Connell D, Peterson J, Welch V, Losos M, et al. The Newcastle-Ottawa Scale (NOS) for Assessing the Quality of Nonrandomised Studies in Meta-Analyses. Available online at: http://www.ohri.ca/programs/ clinical_epidemiology/oxford.asp (2018) (Accessed December 10, 2018).

21. DerSimonian R, Laird N. Meta-analysis in clinical trials. Control Clin Trials (1986) 7:177-88. doi: 10.1016/0197-2456(86)90046-2

22. Higgins JP, Thompson SG. Quantifying heterogeneity in a meta-analysis. Stat Med. (2002) 21:1539-58. doi: 10.1002/sim.1186

23. Begg CB, Mazumdar M. Operating characteristics of a rank correlation test for publication bias. Biometrics (1994) 50:1088-101. doi: 10.2307/2533446

24. Egger M, Davey Smith G, Schneider M, Minder C. Bias in metaanalysis detected by a simple, graphical test. BMJ (1997) 315:629-34. doi: 10.1136/bmj.315.7109.629

25. Thompson SG, Sharp SJ. Explaining heterogeneity in meta-analysis: a comparison of methods. Stat Med. (1999) 18:2693-708. doi: 10.1002/ (SICI)1097-0258(19991030)18:20<2693::AID-SIM235>3.0.CO;2-V

26. Duval S, Tweedie R. Trim and fill: a simple funnel-plot-based method of testing and adjusting for publication bias in metaanalysis. Biometrics (2000) 56:455-63. doi: 10.1111/j.0006-341X.2000. 00455.x

27. Sinner P, Folsom AR, Harnack L, Eberly LE, Schmitz KH. The association of physical activity with lung cancer incidence in a cohort of older women: the Iowa Women's Health Study. Cancer Epidemiol Biomarkers Prev. (2006) 15:2359-63. doi: 10.1158/1055-9965.EPI-06-0251

28. Steindorf K, Friedenreich C, Linseisen J, Rohrmann S, Rundle A, Veglia F, et al. Physical activity and lung cancer risk in the European Prospective Investigation into Cancer and Nutrition Cohort. Int J Cancer (2006) 119:2389-97. doi: 10.1002/ijc.22125

29. Lam TK, Moore SC, Brinton LA, Smith L, Hollenbeck AR, Gierach GL, et al. Anthropometric measures and physical activity and the risk of lung cancer in never-smokers: a prospective cohort study. PLoS ONE (2013) 8:e70672. doi: 10.1371/journal.pone.0070672

30. Leitzmann MF, Koebnick C, Abnet CC, Freedman ND, Park Y, Hollenbeck A, et al. Prospective study of physical activity and lung cancer by histologic type in current, former, and never smokers. Am J Epidemiol. (2009) 169:542-53. doi: $10.1093 / \mathrm{aje} / \mathrm{kwn} 371$
31. Paffenbarger RS,Jr, Hyde RT, Wing AL. Physical activity and incidence of cancer in diverse populations: a preliminary report. Am J Clin Nutr. (1987) 45(1 Suppl.):312-7. doi: 10.1093/ajcn/45.1.312

32. Bak H, Christensen J, Thomsen BL, Tjonneland A, Overvad K, Loft S, et al. Physical activity and risk for lung cancer in a Danish cohort. Int J Cancer (2005) 116:439-44. doi: 10.1002/ijc.21085

33. Jee Y, Kim Y, Jee SH, Ryu M. Exercise and cancer mortality in Korean men and women: a prospective cohort study. BMC Public Health (2018) 18:761. doi: 10.1186/s12889-018-5669-1

34. Knekt P, Raitasalo R, Heliovaara M, Lehtinen V, Pukkala E, Teppo L, et al. Elevated lung cancer risk among persons with depressed mood. Am J Epidemiol. (1996) 144:1096-103. doi: 10.1093/oxfordjournals.aje.a008887

35. Albanes D, Blair A, Taylor PR. Physical activity and risk of cancer in the NHANES I population. Am J Public Health (1989) 79:744-50. doi: 10.2105/AJPH.79.6.744

36. Severson RK, Nomura AM, Grove JS, Stemmermann GN. A prospective analysis of physical activity and cancer. Am J Epidemiol. (1989) 130:522-9. doi: 10.1093/oxfordjournals.aje.a115366

37. Thune I, Lund $\mathrm{E}$. The influence of physical activity on lung-cancer risk: a prospective study of 81,516 men and women. Int J Cancer (1997) 70:57-62. doi: 10.1002/(SICI)1097-0215(19970106)70:1<57::AID-IJC9>3.0.CO;2-5

38. Wannamethee SG, Shaper AG, Walker M. Physical activity and risk of cancer in middle-aged men. Br J Cancer (2001) 85:1311-6. doi: 10.1054/bjoc.2001.2096

39. Colbert LH, Hartman TJ, Tangrea JA, Pietinen P, Virtamo J, Taylor PR, et al. Physical activity and lung cancer risk in male smokers. Int J Cancer (2002) 98:770-3. doi: 10.1002/ijc.10156

40. Sormunen J, Backmand HM, Sarna S, Kujala UM, Kaprio J, Dyba T, et al. Lifetime physical activity and cancer incidence-a cohort study of male former elite athletes in Finland. J Sci Med Sport (2014) 17:479-84. doi: 10.1016/j.jsams.2013.10.239

41. Emaus A, Thune I. Physical activity and lung cancer prevention. Recent Results Cancer Res. (2011) 186:101-33. doi: 10.1007/978-3-642-04231-7_5

42. Friedenreich CM, Neilson HK, Lynch BM. State of the epidemiological evidence on physical activity and cancer prevention. Eur J Cancer (2010) 46:2593-604. doi: 10.1016/j.ejca.2010.07.028

43. Wasswa-Kintu S, Gan WQ, Man SF, Pare PD, Sin DD. Relationship between reduced forced expiratory volume in one second and the risk of lung cancer: a systematic review and meta-analysis. Thorax (2005) 60:570-5. doi: 10.1136/thx.2004.037135

44. Campbell KL, Foster-Schubert KE, Alfano CM, Wang CC, Wang CY, Duggan $\mathrm{CR}$, et al. Reduced-calorie dietary weight loss, exercise, and sex hormones in postmenopausal women: randomized controlled trial. J Clin Oncol. (2012) 30:2314-26. doi: 10.1200/JCO.2011.37.9792

45. Abramson JL, Vaccarino V. Relationship between physical activity and inflammation among apparently healthy middle-aged and older US adults. Arch Intern Med. (2002) 162:1286-92. doi: 10.1001/archinte.162.11.1286

46. Azad N, Rojanasakul Y, Vallyathan V. Inflammation and lung cancer: roles of reactive oxygen/nitrogen species. J Toxicol Environ Health B Crit Rev. (2008) 11:1-15. doi: 10.1080/10937400701436460

47. Soares JP, Silva AM, Oliveira MM, Peixoto F, Gaivao I, Mota MP. Effects of combined physical exercise training on DNA damage and repair capacity: role of oxidative stress changes. Age (Dordr) (2015) 37:9799. doi: 10.1007/s11357-015-9799-4

48. Prasad S, Gupta SC, Pandey MK, Tyagi AK, Deb L. Oxidative stress and cancer: advances and challenges. Oxid Med Cell Longev. (2016) 2016:5010423. doi: $10.1155 / 2016 / 5010423$

Conflict of Interest Statement: The authors declare that the research was conducted in the absence of any commercial or financial relationships that could be construed as a potential conflict of interest.

Copyright $\odot 2019$ Liu, Li, Bai and Fan. This is an open-access article distributed under the terms of the Creative Commons Attribution License (CC BY). The use, distribution or reproduction in other forums is permitted, provided the original author(s) and the copyright owner(s) are credited and that the original publication in this journal is cited, in accordance with accepted academic practice. No use, distribution or reproduction is permitted which does not comply with these terms. 